\title{
Study on Technological Innovation Outsourcing in Scientific and Technological Small and Medium-sized Enterprises Based on Motives
}

\author{
Xiaolin Li \\ School of Management, Xi'an University of Science and Technology \\ Xi' an 710054, China \\ E-mail: fastlx1@yahoo.com.cn
}

Received: March 17, 2011 Accepted: April 21, $2011 \quad$ doi:10.5539/ass.v7n8p233

\begin{abstract}
For the time being, technological innovation outsourcing has become an important channel for enterprises, especially in scientific and technological small and medium-sized enterprises. Based on characteristics of scientific and technological small and medium-sized enterprises, this article made an analysis in the motives and the existing problems. First of all, the author analyzed the motives in four aspects. Then, the author pointed out problems existing in evaluation and selection of outsourcing business of scientific and technological small and medium-sized enterprises, evaluation and selection of outsourcing partners, control over outsourcing activities and adjustment on outsourcing activities. Findings of this article have enlightenments on improving efficiency of technological innovation outsourcing of scientific and technological small and medium-sized enterprises.
\end{abstract}

Keywords: Scientific and technological small and medium-sized enterprises, Technological innovation outsourcing, Motive, Problems

\section{Introduction}

Compared with independent innovation of enterprises, technological innovation outsourcing means that, a technological innovation activity or one aspect of the activity is finished by an outsourcing supplier if the supplier is able to finish the technological innovation activity or a certain aspect of the activity in a more effective way and with lower costs. Otherwise, the activity should be finished by the enterprises themselves. The enterprises may choose outsourcing in any aspect of the technological innovation activity, such as, generation of a new idea, research and development of the technology or commercialized application of the technology, etc.

The group of scientific and technological small and medium-sized enterprises is constituted by 130,000 enterprises in China, approximating to $3 \%$ of the total number of small and medium-sized enterprises. These enterprises have the characteristics of a few funds for establishment, short period of establishment, flexible decision making mechanism, low management cost and the capacity of adapting to diversity of the market, etc. Especially, these enterprises have advantages in terms of innovation mechanism and innovation efficiency that can't be compared by other enterprises, which is where the essence of the group of small and medium-sized enterprises lie and which has always received focus and sufficient affirmation from all circles in the society. However, as a result of some deficiencies of these enterprises, such as, small scale of enterprises, shortage of funds and insufficient capacity, etc., the ability of these enterprises do not equal to their ambition in technological innovation and their efficiency is low. Furthermore, with changes of the contemporary information and faster flow of information, the market poses greater demands on "speed", and the problem of innovation of enterprises becomes more and more complicated. Technological innovation calls for more and more professional knowledge and more professional software support. Under this circumstance, the outsourcing suppliers with more profound skills and competitive strength arise, together with high-efficiency interactive technology. Enterprises are able to get opportunities for faster innovation with lower risks through appropriate development of their central capacity and through practices in outsourcing management.

Ever since the year 1990, there have emerged more and more cases about the technological innovation outsourcing in enterprises. In 2005, the US wireless communication chip enterprise --- Conexant Systems, Inc. outsourced its research and development to the research and development of center in Hyderabad in India, with its employees involved in the outsourcing equaling to those in the research and development center in the headquarter in US. In 2007, Nokia declared to outsource its research and development business of mobile phone 
chip and the major research and development sources within the company were dedicated to other research and development tasks, such as, software development, etc. In the meanwhile, it was reported by the well-known US commercial magazine "Forbes" that the global pharmaceutical enterprises altogether expensed 2 billion US dollars on "outsourcing" of the research and development process in 2003. By the year 2007, expenses on the research and development of the global pharmaceutical enterprises came up to 6 billion US dollars. According to statistics by Antisoma, more than one third companies in the world at present carry out research and development outsourcing, and this proportion increased to $47 \%$ by the year 2008 . All the above indicates that, technological innovation outsourcing has gradually become a newly born enterprise technological innovation mode. The scientific and technological small and medium-sized enterprises have to combine their own characteristics and pay attention to improving the efficiency of outsourcing on the basis of defining the motives of the technological innovation outsourcing. It is exactly on this basis that this article conducted this study.

\section{Motives for technological innovation outsourcing in scientific and technological small and medium-sized enterprises}

\subsection{Economizing funds is the most important reason for "outsourcing" of enterprises}

Scientific and technological small and medium-sized enterprises generally have a small scale and financial strain, especially at the initial period of undertaking the enterprises. If independent innovation is conducted within the enterprises, the enterprises have to conduct continuous research and development, development of human resources and make investment in infrastructure, etc. In addition, the enterprises have to calculate management costs on guidance and support of these internal independent developments and take into account the fact that the project of independent development may lose its competitive advantage as the time goes on. Under pressure of this high expense cost, some enterprises outsource part of their internal research and development task to professional institutions or individuals so as to cut down on design costs on the products, diminish the production period of the products and offer more products with excellent quality and low price for their clients. For example, the US Conexant Systems, Inc. outsources many of its research and development tasks to India and makes full use of local low price human resource costs, which makes their research and development expenses reduced approximately $50 \%$.

\subsection{To diminish the period for research and development of products}

The scientific development changed with each passing day and the cycle for updating of products becomes shorter and shorter. Especially the electronic industry takes the leading in research and developing new products and maintaining the continuously updating enterprises, which will necessarily seize the enormous market shares and share generous profit returns. By contrast, those enterprises with long cycle of research and development can merely obtain odds and ends of the market profits, which will necessarily get eliminated from the overall situation. However, with approaching of the knowledge-oriented economy, any enterprise is unlikely to grasp all information and technology. More and more enterprises gradually lose the ability not equaling to their ambition in the tide of the updating of products. Therefore, quite a large number of enterprises are urgently in need to outsource research and development of their products, diminish the cycle of research and development of their products and adapt to the development of demand of the market. Through cooperation with HTC in Taiwan, PlamOne has developed its best-selling pattern --- Treo650 Smart Phone and effectively diminishes the cycle of research and development of its products to merely several months, with the product defect rate reducing almost one half and the rate of gross profit increasing almost $20 \%$.

\subsection{To strengthen the central capacity of the enterprises}

With accelerated speed of technological progress and demands of consumers in the market, new technology becomes more and more complicated. Resources possessed by scientific and technological small and medium-sized enterprises are always limited, and outsourcing is able to alleviate the burden of these small and medium-sized enterprises. Then, the small and medium-sized enterprises can have a free hand to conduct their own core business and enhance the core competitiveness of the enterprises, which, in turn, can provide powerful motive strength for sustainable development of small and medium-sized enterprises and create conditions for innovation of the small and medium-sized enterprises. Another advantage of outsourcing is that it is able to emancipate the top management personnel and enable them to be dedicated to resolving the central problems in the business of the enterprises.

\subsection{To make up for disadvantages in the capacity}

As a result of constraints of their own funds, capacity and experiences, on one hand, small and medium-sized enterprises might run into some technological difficulties in the process of production that can't be overcome by 
themselves. This might bring about insuperable problems to survival and development of the enterprises. On the other hand, those relevant functions that match with the production might also not give full play to their due effects in auxiliary production, such as, human resource, finance, informationization of the enterprises and sales network, etc., and might even become the obstacle to the entire enterprise. However, the enterprises are able to outsource the business they are not good at to a professional company by the means of outsourcing and then they can make full use of external sources to make up for deficiency of their own capacity.

\section{Problems to be paid attention to}

Scientific and technological small and medium-sized enterprises have to take precautions in selecting the technological innovation outsourcing. They should not merely take into account interest of one party and ignore more potential risks. The enterprises have to make a decision on outsourcing with a systematic and long-term viewpoint. That is to say, the decision making of outsourcing in the enterprises ought to be taken into consideration together with the strategy of the enterprises, so as to enable the outsourcing decision making of the enterprises to become a strategic decision. The reason why outsourcing decision-making of some enterprises has not achieved its anticipated effect is that, to great extent, they are lacking in a procedure as a guiding principle to help the enterprises make a correct decision.

\subsection{Evaluation and selection of outsourcing business}

The decision-making on outsourcing in the enterprises is, essentially, to judge whether it is an issue of internal production or external purchase. First of all, the enterprises have to make an analysis what external purchase includes, raw material, components or other supportive activities and make a judgment whether they are of strategic importance. Strategic importance is reflected in whether these activities are the source of the central competitive strength of the enterprises and source of the competitive advantage of the enterprises. If they fall within the scope of strategic activities, the enterprises should not simply outsource these activities, while they can outsource those non-strategic activities that are unlikely to offer competitive advantages for the enterprises.

\subsection{Evaluation and selection of outsourcing a partner}

One quite important aspect in decision making on outsourcing by the enterprises is to resolve the problem of "who" the business ought to be outsourced to, namely, selection of a partner for outsourcing. First of all, the enterprises should make an evaluation on the external potential suppliers of outsourcing, evaluating their condition of costs in a certain activity, their capacity of long-term development, their reputation, their possibility of assisting the enterprises in reducing costs, improving quality, enhancing the flexibility and strengthening the concentricity of the target. On the basis of the evaluation, the enterprises can then make a comparison between the multiple potential outsourcing partners and select the outsourcing partner that is most appropriate with the requirements of the enterprises.

\subsection{Control over outsourcing activities}

Once the enterprises have decided the outsourcing business and outsourcing cooperative partner, many of them might believe that it is fine and complete in everything. As a matter of fact, control and supervision on the outsourcing activity is the important guarantee for successful implementation of the decision making on outsourcing. Hence, the enterprises need to set up a control mechanism to conduct regular check on the performance of the outsourcing partner and carry out a standard to make assessments on their performance. Only in this way, can the outsourcing business be carried out in a successful way.

\subsection{Adjustment on outsourcing activities}

After the enterprises have conducted outsourcing activities, they also need to make corresponding adjustment on the outsourcing activities in due course according to changes in the external environment and changes in the internal environment. The adjustment at least contains three implications. Firstly, the outsourcing business of the enterprises might need to be altered, former outsourcing business might need to be internalized and new outsourcing business will appear. Secondly, the enterprises will give up outsourcing activities and depend on internal production. Thirdly, the enterprises may consider selecting other outsourcing partners to conduct the outsourcing business. In brief, decision making on outsourcing by the enterprises have to reflect the systematic, long-term, flexible and dynamic characteristics and make implementations and adjustments according to the strategic demand of the enterprises. Only in this way, can the advantages of strategic outsourcing be reflected and can the risks in blind outsourcing be avoided. 


\section{Conclusion}

Quite a large number of scientific and technological small and medium-sized enterprises resort to outsourcing to obtain interests in strategy, management, economy, technology and quality so as to enable the enterprises to keep a sustainable competitive superiority. However, any thing has two sides. At the time when technological innovation outsourcing brings opportunities of benefits to the enterprises, it also implies high risks. Inconsistent targets of the two parties generated by the issue of agency in outsourcing and information asymmetry might give rise to adverse selection and opportunism of outsourcing suppliers, together with uncertain chance occurrence in the environment, etc., will all exert important influences upon realization of the outsourcing value. Thus, scientific and technological small and medium-sized enterprises have to pay attention to selection of appropriate cooperative partners and cultivation of the central capacity of the enterprises, in which way the enterprises are likely to obtain the maximum benefits in technological innovation outsourcing.

\section{References}

Liu, Li. (2006). An Analysis of Advantages and Disadvantages of Technological Innovation Outsourcing. Commercial Times, 17.

Wu, Fengju \& Wang, Deshuang. (2008). Summary of Study on Research and Development Outsourcing of Enterprises and Analysis of the Motives. Management Observer, 10.

Yang, Ying \& Huo, Guoying. (2001). IT Outsourcing in Enterprises and Its Risk Analysis. China Soft Science Magazine, 3.

Zhan, Yongzu \& Yi, Xuefeng. (2002). Study on Technological Innovation Outsourcing in Enterprises. China Soft Science Magazine, 3. 